\title{
Interactions between marine biota and ENSO: a conceptual model analysis
}

\author{
M. Heinemann ${ }^{1}$, A. Timmermann ${ }^{2}$, and U. Feudel ${ }^{3}$ \\ ${ }^{1}$ Max Planck Institute for Meteorology, Bundesstrasse 53, 20146 Hamburg, Germany \\ ${ }^{2}$ IPRC and Dept. of Oceanography, SOEST, University of Hawaii, 1680 East-West Road, Honolulu, Hawaii 96822, USA \\ ${ }^{3}$ ICBM, C. v. O. University of Oldenburg, Carl von Ossietzky Strasse 9-11, 26111 Oldenburg, Germany
}

Received: 20 September 2010 - Revised: 4 December 2010 - Accepted: 6 December 2010 - Published: 21 January 2011

\begin{abstract}
We develop a conceptual coupled atmosphereocean-ecosystem model for the tropical Pacific to investigate the interaction between marine biota and the El NiñoSouthern Oscillation (ENSO). Ocean and atmosphere are represented by a two-box model for the equatorial Pacific cold tongue and the warm pool, including a simplified mixed layer scheme. Marine biota are represented by a three-component (nutrient, phytoplankton, and zooplankton) ecosystem model.

The atmosphere-ocean model exhibits an oscillatory state which qualitatively captures the main physics of ENSO. During an ENSO cycle, the variation of nutrient upwelling, and, to a small extent, the variation of photosynthetically available radiation force an ecosystem oscillation. The simplified ecosystem in turn, due to the effect of phytoplankton on the absorption of shortwave radiation in the water column, leads to (1) a warming of the tropical Pacific, (2) a reduction of the ENSO amplitude, and (3) a prolongation of the ENSO period. We qualitatively investigate these biophysical coupling mechanisms using continuation methods. It is demonstrated that bio-physical coupling may play a considerable role in modulating ENSO variability.
\end{abstract}

\section{Introduction}

The El Niño-Southern Oscillation (ENSO) is the leading global mode of interannual climate variability. Sea surface temperature anomalies (SSTAs) in the central and eastern equatorial Pacific lead to large-scale atmospheric reorganisations and impacts on regional climate not only in the tropical belt but also in remote regions such as Alaska (Wang et al., 2005), Antarctica (Bromwich et al.,

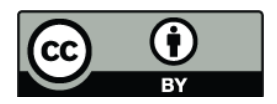

Correspondence to: $\mathrm{M}$. Heinemann (malte.heinemann@zmaw.de)
2004) and even Europe (van Oldenborgh et al., 2000). Its effect on society has generated a lot of interest in ENSO's seasonal predictability. Using dynamical as well as statistical models, climate anomalies associated with ENSO can be predicted several seasons ahead (Latif et al., 1998). Another emerging issue is that of ENSO's sensitivity to future climate change. While some of the state-of-the-art coupled general circulation models simulate an intensification of ENSO variability under $\mathrm{CO}_{2}$ doubling conditions (Timmermann et al., 1999), other models show no significant change or even a weakening of ENSO activity (see Philip and van Oldenborgh, 2006 for a review). Partly, this large uncertainty can be attributed to the simulated differences in the background states and the representation of ENSOrelevant feedbacks, and partly to the different regimes in which ENSO operates in the climate control simulations (Collins et al., 2010).

State-of-the art coupled general circulation models (CGCMs) exhibit severe biases, both in the tropical Pacific climate background state as well as in its annual and interannual variability (Guilyardi et al., 2009). Typically in present-day CGCM simulations, off-equatorial upwelling regions are too warm; whereas the tropical Pacific exhibits cold biases of up to several degrees Celsius. The equatorial Pacific cold bias has a direct influence on the zonal advective feedback which partly determines the simulated statistics of ENSO. Suggestions to remove these biases range from reducing vertical mixing, resolving tropical instability waves and mesoscale ocean variability (Seo et al., 2006), improving stratus cloud parameterisations ( $\mathrm{Yu}$ and Mechoso, 1999; Wang et al., 2004) and including ocean biology (Murtugudde et al., 2002; Timmermann and Jin, 2002; Marzeion et al., 2005).

In fact, using conceptual models of the tropical Pacific, it was demonstrated (Timmermann and Jin, 2002) that the optical properties of chlorophyll might have a significant effect on the simulated vertical distribution of light within

Published by Copernicus Publications on behalf of the European Geosciences Union and the American Geophysical Union. 
the upper ocean. Eventually, changes of radiant heating within the upper water column can lead to significant changes in the sea surface temperature (SST) in the tropical Pacific. Effects of biologically-induced heating on tropical Pacific climate were also found in simulations conducted with ocean models (Nakamoto et al., 2001; Murtugudde et al., 2002; Löptien et al., 2009), atmosphere-ocean hybrid coupled models (Marzeion et al., 2005; Ballabrera-Poy et al., 2007; Zhang et al., 2009), and coupled general circulation models (Manizza et al., 2005; Wetzel et al., 2006; Lengaigne et al., 2007; Anderson et al., 2007, 2009; Gnanadesikan and Anderson, 2009).

To investigate this bio-optical feedback, Timmermann and Jin (2002) used a simple ENSO model coupled to a phytoplankton-temperature relation, which they empirically derived from chlorophyll data fields and the observed Niño 3 SSTAs. The rationale of this approach is that SSTAs strongly determine the equatorial trade winds (Bjerknes, 1969) and equatorial upwelling. This in turn changes the upwelling of nutrients and hence the phytoplankton concentration in the euphotic zone in accordance with observations (Strutton and Chavez, 2004). Consequently, it was found that La Niña is weakened by the presence of phytoplankton, whereas the heating effect on El Niño is small, due to the lack of nutrient supply to the surface waters and hence low chlorophyll concentrations. An important caveat of this study is the very simplified parameterisation of the physical state dependence of chlorophyll.

The aim of this study is to revisit the issue of biological influences on tropical climate using a conceptual physical model for the equatorial Pacific coupled to an ecosystem model that allows a systematic stability analysis and includes the most important influences of the physical environment. These influences are the above mentioned upwelling of nutrients but also the effect of light availability (Chavez et al., 1999; Gildor et al., 2003; Platt et al., 2003). The numerical modelling results presented here are based on a modified version of the conceptual coupled atmosphere-ocean model proposed by Jin (1998) and Timmermann and Jin (2002) coupled to a three-component ecosystem model (Edwards and Brindley, 1996; Edwards, 1997).

The paper is organised as follows: in Sect. 2 the coupled conceptual climate-ecosystem model is introduced. Section 3 contains a description of the default model behaviour, and sensitivity tests regarding the strength of the phytoplankton absorption and the efficiency of upwelling. The emphasis lies on a qualitative analysis, which means that we study the long-term behaviour of the dynamical system and its stability properties with respect to a variation of important parameters. Here the numerical continuation software "CONTENT" (Kuznetsov and Levitin, 1997) is used. The paper concludes with a discussion of our main results (Sect. 4).

\section{Model formulation}

\subsection{Physical model}

The physical model used here is an extended version of Jin's nonlinear recharge model (Jin, 1998) and includes a parametrisation of surface fluxes and mixed layer depth. Figure 1 sketches the structure of the conceptual model used in our study. The equatorial Pacific basin is divided into a western $(i=1)$ and an eastern $(i=2)$ half to distinguish the warm pool and the cold tongue, respectively. The heat budget of each well-mixed surface layer of depth $H_{\mathrm{m}, i}$ is given by

$$
\begin{aligned}
& \frac{d T_{1}}{d t}=\frac{Q_{\mathrm{net}, 1}}{\rho_{\mathrm{w}} c_{\mathrm{p}} H_{\mathrm{m}, 1}}-\frac{u}{L / 2}\left(T_{2}-T_{1}\right) \\
& \frac{d T_{2}}{d t}=\frac{Q_{\mathrm{net}, 2}}{\rho_{\mathrm{w}} c_{\mathrm{p}} H_{\mathrm{m}, 2}}-\frac{w_{2}}{H_{\mathrm{m}, 2}}\left(T_{2}-T_{\mathrm{sub}}\right) .
\end{aligned}
$$

In the following we will discuss the physical mechanisms included in this model. All relevant parameters are listed in Table 1.

The first terms on the right sides of Eqs. (1) and (2) represent the net heating of the surface mixed layer. The net heat flux $Q_{\text {net, } i}$ is calculated as the heat flux entering the mixed layer at the atmosphere-ocean interface $Q_{\mathrm{top}, i}$ minus the fraction of $Q_{\mathrm{top}, i}$ penetrating through the mixed layer base $Q_{\text {bottom, } i}$ (Fig. 1):

$Q_{\text {net }, i}=Q_{\text {top }, i}-Q_{\text {bottom }, i}$.

The surface heat flux is given by

$Q_{\mathrm{top}, i}=Q_{\mathrm{sw}, i}-Q_{\mathrm{lw}, i}-Q_{\mathrm{sens}, i}-Q_{\mathrm{lat}, i}$,

where $Q_{\mathrm{sw}, i}, Q_{\mathrm{lw}, i}, Q_{\mathrm{sens}, i}$, and $Q_{\mathrm{lat}, i}$ denote the net incoming shortwave radiation, outgoing longwave radiation, sensible heat flux, and latent heat of evaporation, respectively. To compute $Q_{\mathrm{sw}, i}$, we assume an annual mean top of atmosphere incoming shortwave radiation of $420 \mathrm{~W} \mathrm{~m}^{-2}$ and a sea surface albedo of 0.09 . Shortwave and longwave radiation as well as latent and sensible heat fluxes are parametrised as described in Gill (1982) and Seager et al. (1988) using empirical relationships for the fractional cloud cover that capture the interannual changes of cloudiness during the ENSO cycle. Long-wave radiation as well as approximately $45 \%$ of the incoming short wave radiation (the "red" fraction) are absorbed within the first meter and thus do not reach the bottom of the mixed layer. Consequently, the heat flux through the mixed layer base is given by

$Q_{\text {bottom }, i}=0.55 Q_{\mathrm{sw}, i} e^{-k_{i} H_{\mathrm{m}, i}}=\operatorname{PAR}_{i} e^{-k_{i} H_{\mathrm{m}, i}}$,

where the factor 0.55 accounts for the remaining blue fraction of the short-wave radiation, and $k_{i}$ is the absorption coefficient for blue light. $\mathrm{PAR}_{i}$ denotes the photosynthetically active radiation in the western $(i=1)$ and eastern box 


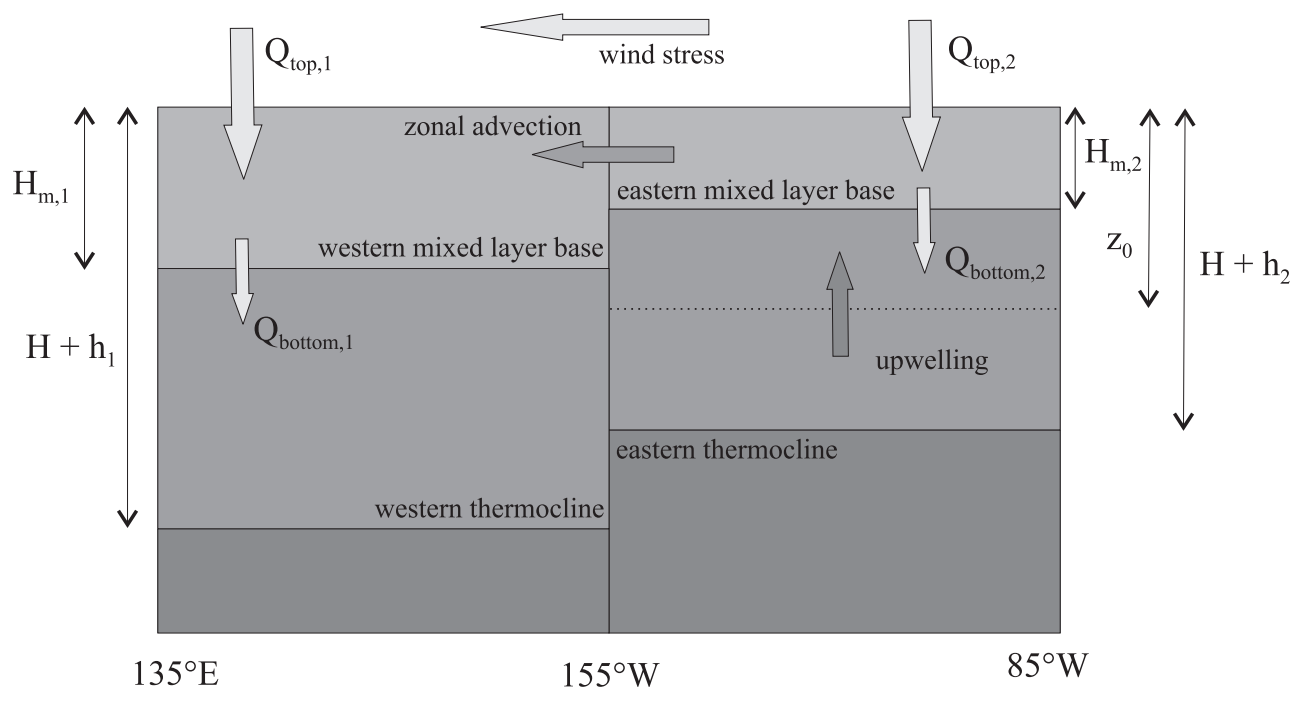

Fig. 1. Box-model of the equatorial Pacific basin. While the zonal advection and wind stress arrows in this figure point westward (indicating the typical situation), the values of $u$ (Eq. 6) and $\tau_{x}$ (Eq. 8) are positive for eastward directions.

Table 1. Parameters relevant for the physical model.

\begin{tabular}{lll}
\hline parameter & default value & description \\
\hline$\epsilon$ & 0.05 & zonal advection efficiency \\
$\zeta$ & 1.3 & vertical advection efficiency \\
$\mu$ & $0.0026 \mathrm{~m}(\mathrm{~K} \text { day })^{-1}$ & atmosphere-ocean coupling coefficient \\
$\phi$ & $(300 \text { days })^{-1}$ & inverse dynamical adjustment timescale \\
$\beta$ & $0.585 \mathrm{~m}^{3}\left(\mathrm{~N} \mathrm{day}^{-1}\right.$ & measures latitudinal variation of Coriolis parameter and momentum mixing rate \\
$b$ & $1.875 \times 10^{-4} \mathrm{~m}^{2} \mathrm{~N}^{-1}$ & measures efficiency of wind stress in driving thermocline tilt \\
$L$ & $15 \times 10^{6} \mathrm{~m}$ & width of Pacific basin \\
$c_{p}$ & $3940 \mathrm{Ws}(\mathrm{kg} \mathrm{K})^{-1}$ & specific heat at constant pressure \\
$\rho_{\mathrm{W}}$ & $1024 \mathrm{~kg} \mathrm{~m}^{-3}$ & water density \\
$H$ & $100 \mathrm{~m}$ & thermocline reference depth \\
$T_{\mathrm{r}}$ & $30^{\circ} \mathrm{C}$ & radiative-convective equilibrium temperature \\
$T_{\mathrm{r} 0}$ & $17^{\circ} \mathrm{C}$ & temperature beneath the thermocline \\
$h^{*}$ & $50 \mathrm{~m}$ & measures thermocline sharpness \\
$\xi$ & 0.5 & determines position of $z_{0}($ Eq. 12) \\
$\Delta T$ & $1 \mathrm{~K}$ & measures external part of zonal wind stress \\
$\epsilon_{0}$ & $7.5 \times 10^{-9} \mathrm{~m}^{2} \mathrm{~s}^{-3}$ & dissipation constant \\
$\tau_{\mathrm{mix}}$ & $0.06 \mathrm{~N} \mathrm{~m}^{-2}$ & background windstress \\
$m_{\mathrm{S}}$ & 1.25 & surface production coefficient \\
$\alpha_{T}$ & $0.00025^{\circ} \mathrm{C}_{-1}$ & thermal expansion coefficient \\
$g$ & $9.81 \mathrm{~m} \mathrm{~s}^{-2}$ & gravitational acceleration \\
\hline
\end{tabular}

$(i=2)$. The seasonal cycle of insolation has been neglected, because the box model used here is not able to capture air-sea interactions associated with the seasonal cycle (Xie, 1996).

The second term on the right side of Eq. (1) denotes zonal advection, the second term on the right side of Eq. (2) represents cooling due to the upwelling of cold subsurface water at the temperature $T_{\text {sub }}$ into the mixed layer. The zonal velocity is given by $u, L$ denotes the basin width, $w_{2}$ is the upwelling velocity into the eastern surface box. Upwelling into the western surface box is assumed to be negligible (i.e., $w_{1}=0$ ). Assuming the surface zonal current to be proportional to the zonal wind stress $\tau_{x}$, the inverse advective 
timescale can be expressed as

$u /(L / 2)=\epsilon \beta \tau_{x}$,

where $\epsilon$ measures the strength of the zonal advection, and $\beta$ is determined by the Coriolis parameter and the momentum mixing rate in the upper ocean (Jin, 1998). Equatorial upwelling into the mixed layer is mainly due to poleward Ekman flow divergence, which is proportional to the zonal wind stress (Neelin, 1991; Jin and Neelin, 1993). Therefore, the total upwelling rate in Eq. (2) can be expressed as

$w_{2} / H_{\mathrm{m}, 2}=-\zeta \beta \tau_{x}$,

with $\zeta$ being a dimensionless coefficient describing the efficiency of upwelling. The zonal wind stress $\tau_{x}$ in the equatorial Pacific is largely due to the Walker circulation, which is driven by the SST gradient across the basin. We write

$\tau_{x}=-\mu\left(T_{1}-T_{2}+\Delta T\right) / \beta$,

where $\mu$ is a dynamical coupling coefficient. The additional temperature difference $\Delta T$ represents wind stress due to the influence of the Hadley circulation on equatorial winds, which is driven by meridional differential heating, and other external heating sources like adjacent land masses (Jin, 1998).

Given the fact that the Kelvin wave adjustment in the real ocean is fast compared to the ENSO timescale, westward wind stress is approximately balanced by pressure gradients in the upper ocean associated with a sea level gradient across the basin and a corresponding thermocline tilt. Therefore the thermocline tilt can be approximated as

$h_{2}-h_{1}=b L \tau_{x}$,

where $h_{1}\left(h_{2}\right)$ denotes the departure of the western (eastern) thermocline depth from the reference depth $H$, and $b$ measures the efficiency of wind stress in driving the thermocline tilt. The western total thermocline depth $H+$ $h_{1}$ adjusts to the zonally integrated Sverdrup meridional mass transport resulting from wind-forced Rossby waves. Rossby waves are much slower than the eastward travelling Kelvin waves. Thus, in our model, the western thermocline adjustment is characterised by the dynamical adjustment timescale $1 / \phi$ :

$\frac{d h_{1}}{d t}=\phi\left(-h_{1}-\frac{b L \tau_{x}}{2}\right)$.

The temperature of the water being upwelled into the mixed layer is given by $T_{\text {sub }}$, imitating a vertically resolved temperature profile. It is parameterised as suggested by Jin (1996):

$T_{\mathrm{sub}}=T_{\mathrm{r}}-\frac{T_{\mathrm{r}}-T_{\mathrm{r} 0}}{2}\left[1-\tanh \left(\frac{H+h_{2}-z_{0}}{h^{*}}\right)\right]$ where $T_{\mathrm{r}}$ denotes the radiative convective equilibrium temperature for the Pacific basin. The temperature below the eastern thermocline is given by $T_{\mathrm{r} 0}, h^{*}$ measures the sharpness of the thermocline, and $z_{0}$ is the depth at which the upwelling velocity $w$ takes its characteristic value. This depth is assumed to lie in between the reference thermocline depth $H$ and the mixed layer base at depth $H_{\mathrm{m}, 2}$ :

$z_{0}=(1-\xi)(H)+\xi H_{\mathrm{m}, 2} \quad$ with $\xi \in[0,1]$.

The computation of the mixed layer depth $H_{\mathrm{m}, i}$ is based on the assumption that entrainment and buoyancy are in quasiequilibrium with the turbulent kinetic energy (TKE) created by wind (Kraus and Turner, 1967) minus the depth dependent background dissipation term $2 \epsilon_{0} H_{\mathrm{m}, i}$ suggested by Schopf and Cane (1983)

$$
\begin{gathered}
\mathcal{H}\left(w_{i}^{\text {entr }}\right) w_{i}^{\text {entr }} H_{\mathrm{m}, i} \Delta b_{i}+H_{\mathrm{m}, i} B_{i} \\
=2 m_{\mathrm{s}} u_{*}^{3}-2 \epsilon_{0} H_{\mathrm{m}, i} .
\end{gathered}
$$

The scaling coefficient $m_{\mathrm{s}}$ times the third power of the friction velocity $u_{*}=\sqrt{\tau / \rho_{\mathrm{W}}}$ describes the TKE created by wind stress at the sea surface. We parameterise the total wind stress $\tau$ as the zonal wind stress $\tau_{x}$ (Eq. 8) with an additional constant background windstress $\tau_{\text {mix }}$ representing a mean gustiness, such that $\tau=\sqrt{\tau_{x}^{2}+\tau_{\operatorname{mix}}^{2}} \cdot \mathcal{H}$ denotes the Heaviside function, and $w_{i}^{\text {entr }}$ is the mixed layer entrainment velocity characterising the mass flux across the mixed layer base (Schopf and Cane, 1983). On interannual timescales, the entrainment velocity can be approximated by the upwelling velocity $w_{i}$. The factor $\Delta b_{i}$ describes the buoyancy difference between the surface water and the water below the mixed layer. Note that $\mathcal{H}\left(w_{1}\right) w_{1} \Delta b_{1}$ vanishes because $w_{1}=0$. The buoyancy difference $\Delta b_{2}$ in the western box can be expressed as $\alpha_{T} g 0.1\left(T_{2}-T_{\mathrm{sub}}\right)$, where $\alpha_{T}$ describes the logarithmic expansion of the water density $\rho_{\mathrm{w}}$ as a function of temperature, $g$ is the gravitational acceleration, and the temperature difference $0.1\left(T_{2}-T_{\text {sub }}\right)$ is chosen such as to obtain realistic interannual variations of the mixed layer depth. The buoyancy flux $B_{i}$ into the mixed layer is given by $B_{i}=\alpha_{T} g Q_{\text {net }, i} /\left(\rho_{\mathrm{w}} c_{\mathrm{p}}\right)$. Note that $Q_{\text {net }, i}$ is a function of $H_{\mathrm{m}, i}$ itself (Eqs. 3-5), which means that Eq. (13) is nonlinear, and we solve it iteratively to compute the mixed layer depths $H_{\mathrm{m}, i}$.

\subsection{Ecosystem model}

Marine biology in the eastern equatorial Pacific is represented by a simplified ecosystem model that has three compartments: nutrients, phytoplankton and zooplankton. It is a modification of the three-component ecosystem model investigated by Edwards and Brindley (1996), which they in turn derived from that of Steele and Henderson (1981). Modifications were necessary in order to adjust it to the equatorial Pacific and to involve the interannual 
change of nutrient availability associated with the El NiñoSouthern Oscillation as described below. Phytoplankton concentrations in the Pacific warm pool are relatively low compared to those in the cold tongue and do not vary so much on an interannual timescale (Barber and Chavez, 1983; Chavez et al., 1999). Consequently, the dynamical equations for the ecosystem model are only applied to the eastern equatorial Pacific box, which represents the cold tongue.

We assume that phytoplankton growth is restricted to the surface mixed layer, as already outlined by Edwards and Brindley (1996). Our three components - nutrients N, phytoplankton $\mathrm{P}$, and zooplankton $\mathrm{Z}$ - are assumed to be homogeneously distributed within this layer. The biological system can then be represented by three coupled ordinary differential equations:

$$
\begin{aligned}
\frac{d \mathrm{~N}}{d t}= & -\frac{\mathrm{N}}{e+\mathrm{N}} \frac{a}{k_{\mathrm{w}}+k_{\mathrm{c}} \mathrm{P}} \mathrm{P}+r \mathrm{P}+\frac{\eta \lambda \mathrm{P}^{2}}{v^{2}+\mathrm{P}^{2}} \mathrm{Z} \\
& +\gamma d \mathrm{Z}^{2}+\frac{w_{2}}{H_{\mathrm{m}, 2}}\left(\mathrm{~N}_{0}-\mathrm{N}\right) \\
= & - \text { uptake }+ \text { recycling of } \mathrm{P}+\text { excretion by } \mathrm{Z} \\
& + \text { recycling of } \mathrm{Z}+\text { upwelling }
\end{aligned}
$$

$$
\begin{aligned}
\frac{d \mathrm{P}}{d t}= & \frac{\mathrm{N}}{e+\mathrm{N}} \frac{a}{k_{\mathrm{w}}+k_{\mathrm{c}} \mathrm{P}} \mathrm{P}-r \mathrm{P}-\frac{\lambda \mathrm{P}^{2}}{v^{2}+\mathrm{P}^{2}} \mathrm{Z} \\
& -s \mathrm{P}+\frac{w_{2}}{H_{\mathrm{m}, 2}}\left(\mathrm{P}_{0}-\mathrm{P}\right) \\
= & \text { uptake }- \text { respiration }- \text { grazing } \\
& - \text { sinking }+ \text { upwelling }
\end{aligned}
$$

$$
\begin{aligned}
\frac{d \mathrm{Z}}{d t} & =\frac{\alpha \lambda \mathrm{P}^{2}}{v^{2}+\mathrm{P}^{2}} \mathrm{Z}-d \mathrm{Z}^{2} \\
& =\text { growth }- \text { higher predation and natural mortality. }
\end{aligned}
$$

All relevant parameters and their default values are listed in Table 2. The primary production described by the first terms in Eqs. (14) and (15) is determined by nutrient and light availability. Nutrient limitation is represented by the Michaelis-Menten function $\mathrm{N} /(e+\mathrm{N})$. Variation of shortwave radiation is involved via the depth-averaged primary production term $a \mathrm{P} /\left(k_{\mathrm{w}}+k_{\mathrm{c}} \mathrm{P}\right)$. The functional dependence of $a$ on the PAR is adopted from Platt et al. (2003). Further, $k_{\mathrm{W}}$ is the vertical attenuation coefficient for blue light in seawater. The term $k_{\mathrm{c}} \mathrm{P}$ accounts for phytoplankton self-shading, where $k_{\mathrm{c}}$ is the biomass-specific vertical PAR attenuation coefficient. We suppose that the ocean beneath the mixed layer is a reservoir with a constantly high nutrient concentration $\mathrm{N}_{0}$, but no phytoplankton $\left(\mathrm{P}_{0}=\right.$ $0)$. Zooplankton is assumed to be mobile enough to be independent of the upwelling process. In contrast to Edwards and Brindley (1996), who define a thermocline exchange rate that is either constant or dependent on the change of the mixed layer depth, our exchange rate is defined as $w_{2} / H_{\mathrm{m}, 2}$. It parameterises dilution of phytoplankton as well as upwelling of nutrients. Phytoplankton respiration and natural mortality are represented by the linear loss term $-r \mathrm{P}$. This loss is recycled immediately into nutrient. By contrast, the linear sinking term $-s \mathrm{P}$ is not recycled. Zooplankton grazing is represented by a sigmoidal Holling type III term, $\lambda \mathrm{P}^{2} /\left(v^{2}+\mathrm{P}^{2}\right)$, with maximum zooplankton grazing rate $\lambda$ and half-saturation constant $v$. Only a fraction of this term turns into zooplankton biomass. This fraction is given by the zooplankton growth efficiency $\alpha$. Another fraction $\eta$ represents zooplankton excretion. The carnivore population is assumed to change in proportion to the zooplankton population. Thus, higher predation of zooplankton is modeled by the quadratic term $-d \mathrm{Z}^{2}$.

\subsection{Coupling mechanisms}

The physical model and the biological model as described above (Sects. 2.1 and 2.2) are coupled to each other as follows.

The physical system influences the simplified ecosystem model via the variability of shortwave radiation and upwelling. An increase of the incoming shortwave radiation causes higher phytoplankton concentrations, since the photosynthesis-irradiance curve in our model is monotonically increasing. Since nutrients and phytoplankton are assumed to be unable to move against currents, their concentration within the mixed layer is strongly influenced by the upwelling rate $w_{2} / H_{\mathrm{m}, 2}$, as documented in observational data (Strutton and Chavez, 2004). With regard to Eq. (14), we expect an increased upwelling rate to cause an increased nutrient concentration within the mixed layer and thus increased phytoplankton growth. However, increased upwelling also leads to a stronger dilution of phytoplankton (Eq. 15). Zooplankton, since it is assumed to move independently of upwelling, only responds to a changed phytoplankton concentration, but is not directly affected by a variation of $w_{2} / H_{\mathrm{m}, 2}$.

Marine biology affects the physical system via the absorption of blue light by phytoplankton. Here, the phytoplankton concentration $\mathrm{P}$ only attains non-zero values in the eastern equatorial surface mixed layer. Hence, the absorption coefficients are given by

$k_{1}=k_{\mathrm{w}}$ and $k_{2}=k_{\mathrm{w}}+k_{\mathrm{c}} \mathrm{P}$

for the western and eastern equatorial Pacific, respectively. We assume a zero background chlorophyll concentration; a non-zero background concentration could be imitated by increasing the value of the light attenuation by water $k_{\mathrm{W}}$ (Edwards et al., 2003). 
Table 2. Parameters relevant for the ecosystem model; for the parameter conversions, a carbon to chlorophyll ratio of $50 \mathrm{mg} \mathrm{C}(\mathrm{mg} \mathrm{chl})^{-1}$, and a nitrate to chlorophyll ratio of $0.1 \mathrm{gC}(\mathrm{mmol} \mathrm{N})^{-1}$ were assumed (Edwards, 1997).

\begin{tabular}{lll}
\hline parameter & default value & description \\
\hline$k_{\mathrm{W}}$ & $0.046 \mathrm{~m}^{-1}$ & light attenuation by water (Platt et al., 2003) \\
$k_{\mathrm{c}}$ & $0.74 \mathrm{~m}^{2}(\mathrm{gC})^{-1}$ & $\begin{array}{l}\text { biomass-specific attenuation coefficient (Platt et al., 2003) } \\
d\end{array}$ \\
$1.0 \mathrm{~m}^{3}\left(\mathrm{gC} \mathrm{day}^{-1}\right.$ & higher predation and natural mortality of Z (Edwards, 1997) \\
$e$ & $0.11 \mathrm{gC} \mathrm{m}^{-3}$ & half saturation for N uptake (Gildor et al., 2003) \\
$r$ & $0.13 \mathrm{day}^{-1}$ & P respiration rate (Gildor et al., 2003) \\
$s$ & $0.04 \mathrm{day}^{-1}$ & P sinking loss rate (Edwards, 1997) \\
$\mathrm{N}_{0}$ & $0.6 \mathrm{gC} \mathrm{m}^{-3}$ & N concentration below mixed layer (Edwards, 1997) \\
$\alpha$ & 0.25 & Z growth efficiency (Edwards, 1997) \\
$\eta$ & 0.33 & Z excretion fraction (Edwards, 1997) \\
$\gamma$ & 0.5 & regeneration of Z predation (Edwards, 1997) \\
$\lambda$ & $0.6 \mathrm{day}^{-1}$ & maximum Z grazing rate (Edwards, 1997) \\
$v$ & $0.05 \mathrm{gC} \mathrm{m}^{-3}$ & Z grazing half-saturation (Edwards, 1997) \\
\hline
\end{tabular}

Increasing the absorption coefficient means that more short-wave radiation is absorbed within the mixed layer. Consequently, the mean temperature of the mixed layer rises. It should be mentioned here that the heat lost beneath the mixed layer cannot be recycled within our simplified model. A better representation of this effect requires a two-layer model with an embedded mixed layer. Without biology, the absorption of light is given by $k_{\mathrm{w}}=0.046 \mathrm{~m}^{-1}$.

A higher (lower) phytoplankton concentration in the eastern equatorial Pacific means that less (more) PAR penetrates through the bottom of the mixed layer. Hence, the net heat flux into the mixed layer $Q_{\text {net,2 }}$ is increased (reduced). From Eq. (2), we expect that $T_{2}$ is increased (decreased). However, the response is more complex since a variation of $Q_{\text {net,2 }}$ and the zonal temperature gradient $T_{1}-T_{2}$ also affects the mixed layer depth as well as the zonal wind stress.

The coupling mechanisms suggest two parameters to be important to quantify the strength of the feedback mechanisms between physics and biology. The first parameter is the upwelling efficiency $\zeta$, which determines nutrient supply, an important impact of the physical system on the ecosystem. The second one is the phytoplankton dependent light attenuation coefficient $k_{\mathrm{c}}$, which determines the biofeedback on the physical system. We will use $\zeta$ and $k_{\mathrm{c}}$ as bifurcation parameters in the following section.

\section{Model results}

\subsection{Default ENSO and marine biology}

Integrating the coupled bio-physical model as described by the differential Eqs. (1), (2), (10), and (14)-(16) for the default parameter values given in Tables 1 and 2 yields an

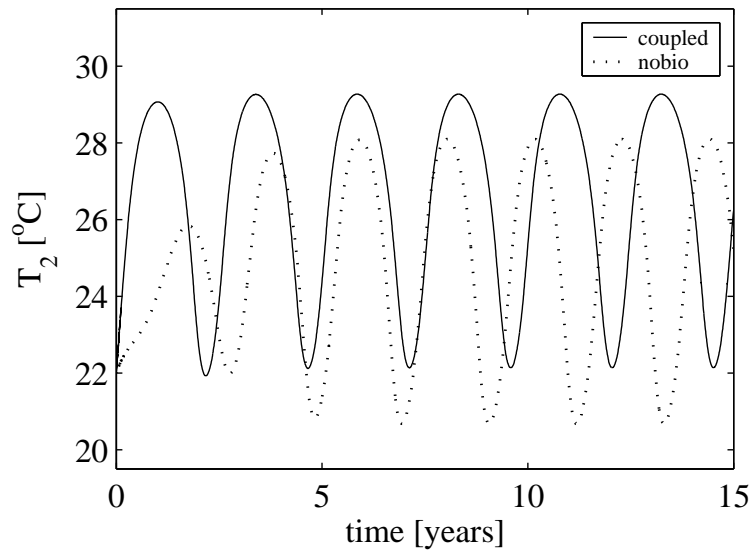

Fig. 2. Eastern equatorial Pacific SST $T_{2}$ for the default run of the fully coupled model (solid line, parameters from Tables 1 and 2, $k_{\mathrm{c}}=0.74 \mathrm{~m}^{2}(\mathrm{gC})^{-1}$ ) compared to a run without biology (dotted line, $\left.k_{\mathrm{c}}=0\right)$.

oscillatory state of the system. After a short transitional phase, the SST in the eastern equatorial box varies between $22.1^{\circ} \mathrm{C}$ and $29.2^{\circ} \mathrm{C}$; the period of the simulated ENSO cycle amounts to about 2.5 years (Fig. 2). Note that the period and amplitude of the oscillation strongly depend on the parameter choice. For example, reducing the coefficient $\mu$, which describes the coupling between ocean and atmosphere, leads to a longer period, but also reduces the amplitude. The period can also be varied via the inverse dynamical adjustment timescale $\phi$ (Eq. 10). For our purpose of analysing the qualitative impact of feedbacks between physical and biological processes, the exact value of the period is not important. 
a)

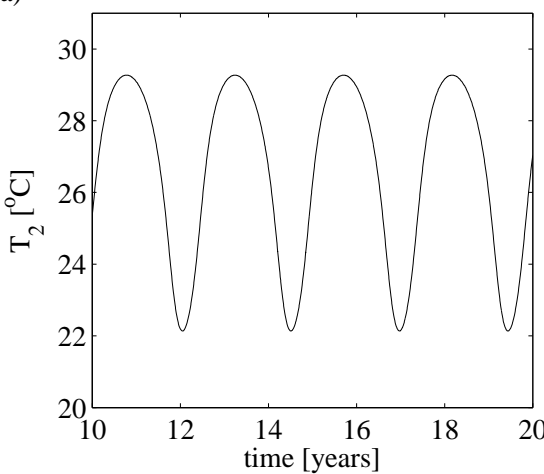

d)

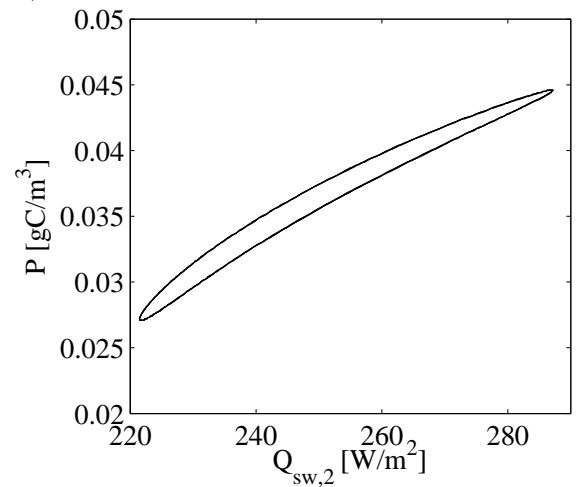

b)

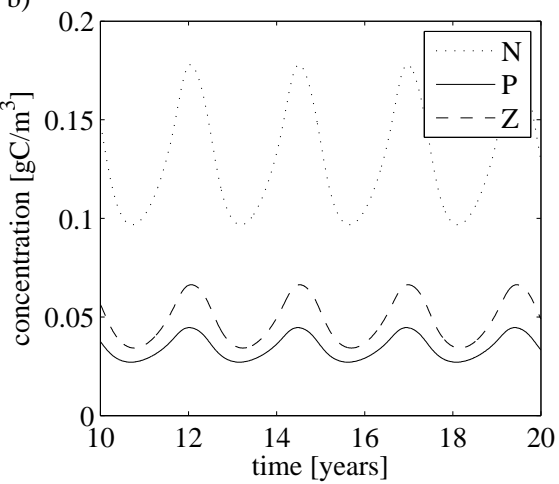

e)

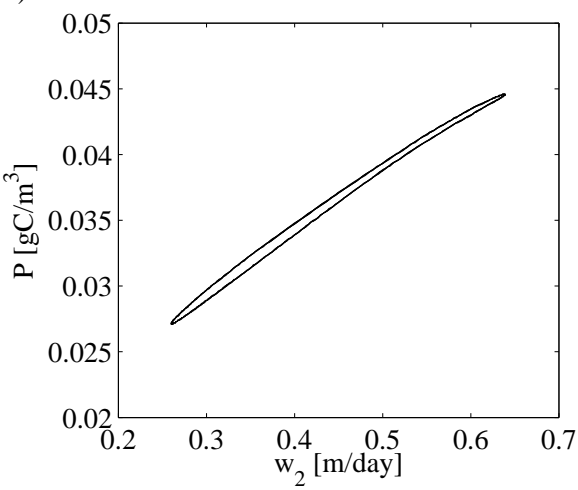

c)

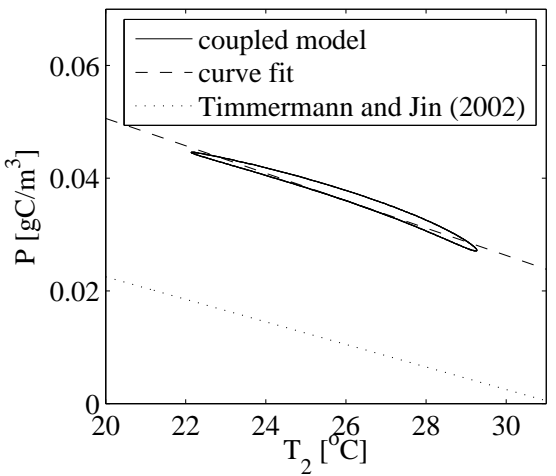

f)

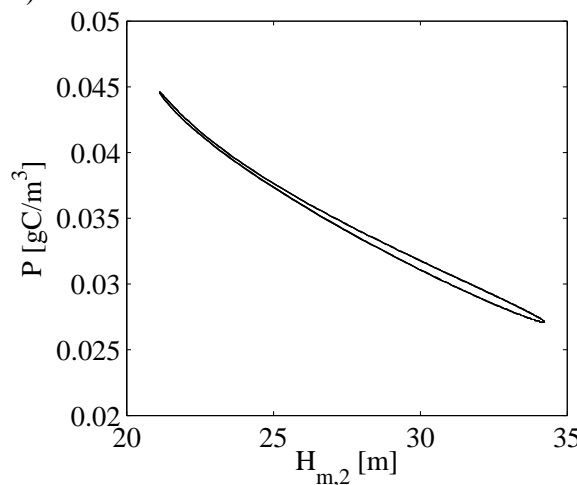

Fig. 3. (a) Timeseries of the eastern SST $T_{2}$; (b) timeseries of the nutrient concentration $\mathrm{N}$, phytoplankton P and zooplankton Z; (c) phasespace plot of phytoplankton $\mathrm{P}$ vs. eastern $\mathrm{SST} T_{2}$ (solid line), least square curve fit (dashed line; $\mathrm{P}=-0.0273 \mathrm{gC} \mathrm{m}^{-3}-0.0024 \mathrm{gC}^{-3}{ }^{\circ} \mathrm{C}^{-1}$ $\left(T_{2}-30^{\circ} \mathrm{C}\right)$ ), and chlorophyll-temperature relation as used by Timmermann and Jin (2002) (dotted line, for a strong bio-physical coupling $\mathrm{P}=-0.0025 \mathrm{gC} \mathrm{m}^{-3}-0.0020 \mathrm{gC} \mathrm{m}^{-3}{ }^{\circ} \mathrm{C}^{-1}\left(T_{2}-30{ }^{\circ} \mathrm{C}\right)$, assuming a chlorophyll to carbon ratio of $\left.50 \mathrm{mg} \mathrm{C}(\mathrm{mg} \mathrm{chl})-1\right) ;(\mathbf{d})-(\mathbf{f}) \mathrm{phase}^{-}$ space plots of phytoplankton $\mathrm{P}$ vs. short-wave heatflux $Q_{\mathrm{sw}, 2}$, upwelling velocity $w_{2}$ and eastern mixed layer depth $H_{\mathrm{m}, 2}$; parameters from Tables 1 and 2 .

The stand-alone ecological system relaxes towards a stable equilibrium with a phytoplankton concentration of about $0.035 \mathrm{gC} \mathrm{m}^{-3}$ (not shown). In the coupled model, the ecosystem shows an oscillation which is forced by ENSO (Fig. 3). Phytoplankton concentrations are high during La Niña (about $0.045 \mathrm{gC} \mathrm{m}^{-3}$ ) and relatively low during El Niño $\left(0.027 \mathrm{gC} \mathrm{m}^{-3}\right)$. Assuming a carbon to chlorophyll ratio of $\chi=50 \mathrm{mgC}(\mathrm{mg} \mathrm{chl})^{-1}$ (Edwards, 1997), the high simulated phytoplankton concentration during La Niña roughly matches the (very high) observed chlorophyll concentration of $1 \mathrm{mg} \mathrm{chl} \mathrm{m}^{-3}$ over wide areas of the equatorial Pacific cold tongue in July 1998 (Chavez et al., 1999). However, comparability strongly depends on the uncertain chlorophyll to carbon ratio. For example, Platt et al. (2003) report a maximum carbon to chlorophyll ratio of $150 \mathrm{mgC}(\mathrm{mg} \mathrm{chl})^{-1}$, which would imply that the simulated maximum chlorophyll concentration is much lower than the observed maximum. Moreover, the chlorophyll to carbon ratio changes as phytoplankton adapts to its abiotic environment (Cloern et al., 1995; Taylor et al., 1997).
In our default coupled model simulation, the shortwave radiation at the surface of the eastern equatorial Pacific $Q_{\text {sw,2 }}$ increases from $220 \mathrm{~W} \mathrm{~m}^{-2}$ during El Niño to about $290 \mathrm{~W} \mathrm{~m}^{-2}$ during La Niña (Fig. 3d) due to a reduction of the cloud fraction (cf. Sect. 2.1). In the stand-alone ecosystem model, this heatflux increase causes a small phytoplankton concentration increase of about $0.001 \mathrm{gC} \mathrm{m}^{-3}$, which amounts to about $6 \%$ of the phytoplankton variability during an ENSO cycle (applying a mixed layer depth of $30 \mathrm{~m}$ and an upwelling velocity of $0.5 \mathrm{~m} \mathrm{day}^{-1}$ as boundary conditions). The upwelling velocity $w_{2}$ increases from $0.25 \mathrm{~m}$ day $^{-1}$ during El Niño to about $0.65 \mathrm{~m} \mathrm{day}^{-1}$ during La Niña (Fig. 3e). The response of the stand-alone ecosystem model to that enhanced upwelling is an increase of the phytoplankton concentration by about $0.009 \mathrm{gC} \mathrm{m}^{-3}$, which amounts to $50 \%$ of the phytoplankton variability during an ENSO cycle (applying a mixed layer depth of $30 \mathrm{~m}$ and an incoming shortwave radiation of $250 \mathrm{~W} \mathrm{~m}^{-2}$ as boundary conditions). This response is almost an order of magnitude bigger than the response to the variation of the shortwave radiation. Moreover, the mixed layer depth decreases 
a)

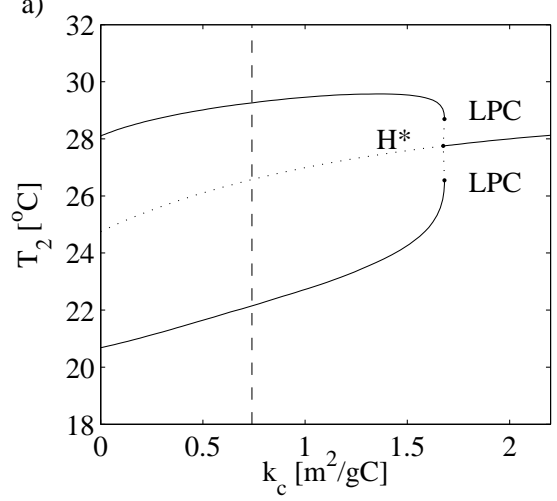

d)

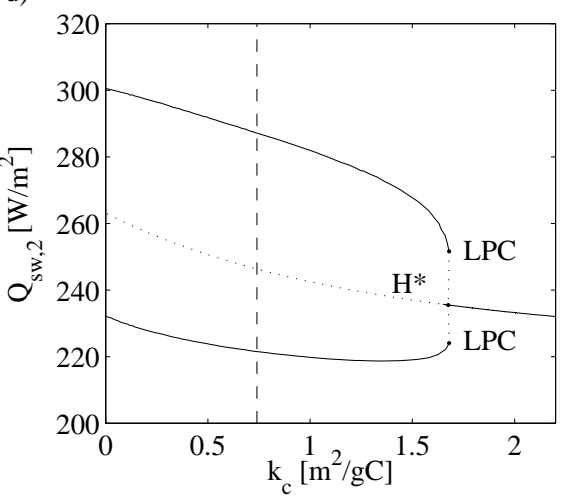

b)

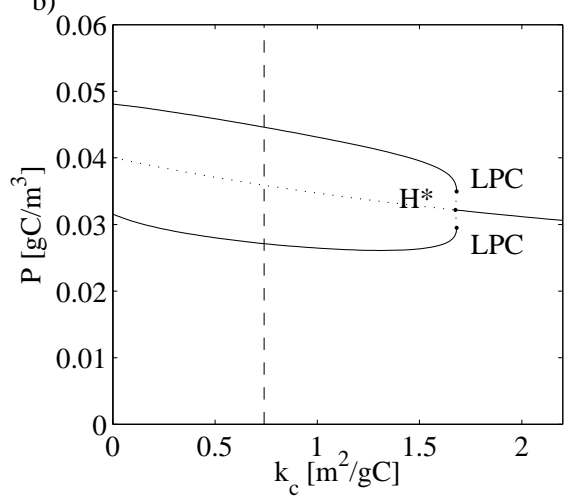

e)

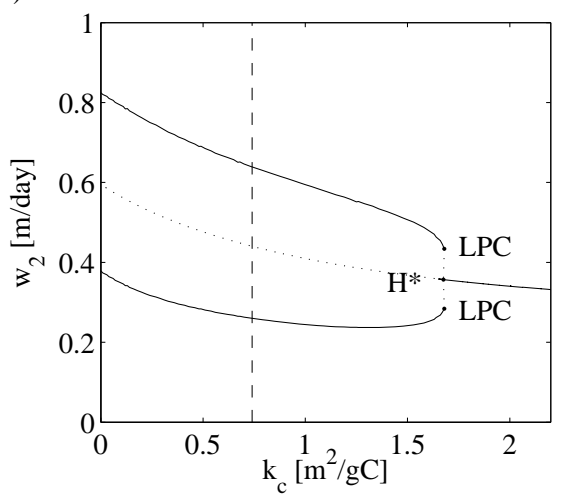

c)

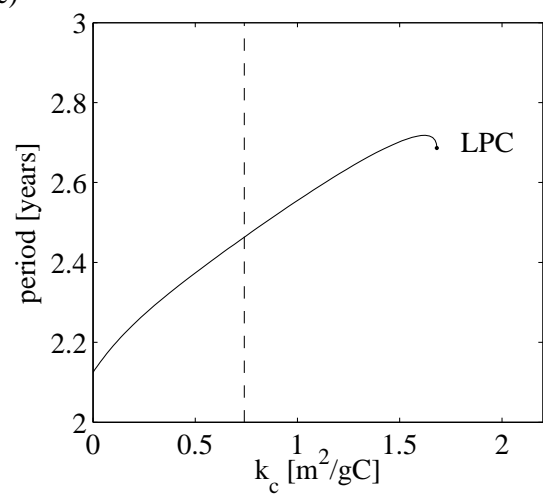

f)

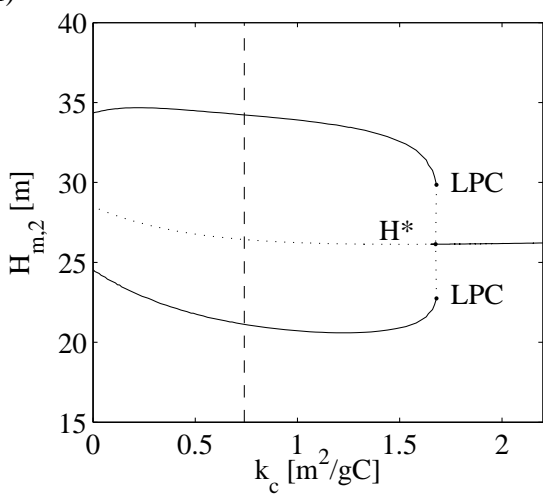

Fig. 4. Variations in response to changes of the biomass-specific self-shading coefficient $k_{\mathrm{c}}$ for (a) eastern SST $T_{2}$, (b) eastern phytoplankton concentration P, (c) ENSO period, (d) incoming short-wave heatflux $Q_{\mathrm{sw}, 2}$, (e) upwelling velocity $w_{2}$, and (f) eastern mixed layer depth $H_{\mathrm{m}, 2} ; \mathrm{H}^{*}$ : subcritical Hopf bifurcation; LPC: limit point of cycles; solid lines: minimum and maximum of stable oscillation or stable steady state respectively; dotted lines: minimum and maximum of unstable oscillation or unstable steady state; dashed line: default value $k_{\mathrm{c}}=0.74 \mathrm{~m}^{2}(\mathrm{gC})^{-1}$.

from about $34 \mathrm{~m}$ during El Niño to about $21 \mathrm{~m}$ during La Niña (Fig. 3f). Similar to an increase in the upwelling velocity, a decrease in the mixed layer depth leads to a larger thermocline exchange rate $w_{2} / H_{\mathrm{m}, 2}$ in our model; the decreased mixed layer depth during La Niña also causes a larger phytoplankton concentration. Summing up, changes in the phytoplankton concentration in our model are mostly caused by a variation of the thermocline exchange rate rather than by the variation of the incoming shortwave radiation.

\subsection{Biological feedbacks on ENSO}

The strength of the biological feedback is determined by the biomass-specific attenuation coefficient $k_{\mathrm{c}}$. Note that $k_{\mathrm{c}}=0$ corresponds to the physical model without biology. For our default value $k_{\mathrm{c}}=0.74 \mathrm{~m}^{2}(\mathrm{gC})^{-1}$, which is typical for the equatorial Pacific (Platt et al., 2003), the minimum eastern SST $T_{2}$ during La Niña is increased by $1.5^{\circ} \mathrm{C}$, the maximum is increased by $1.1^{\circ} \mathrm{C}$ (Figs. 2 and $4 \mathrm{a}$ ). Moreover, for the default $k_{\mathrm{c}}$, marine biology prolongates the ENSO cycle by about 3 months (Figs. 2 and 4c).
A stronger biomass-specific absorption $k_{\mathrm{c}}$ means that less short-wave radiation leaves the bottom of the mixed layer. The subsequent heating of the eastern surface water causes an increased cloud fraction (cf. Sect. 2.1) and thus decreased incoming short-wave radiation (Fig. 4d). Since the western SST $T_{1}$ increases less than the eastern SST $T_{2}$ (not shown), the difference $T_{1}-T_{2}$ and thus the zonal wind stress $\tau_{x}$ is reduced (Eq. 8). Accordingly, upwelling is diminished (Fig. 4e) and phytoplankton concentrations decrease (Fig. 4b).

Increasing the strength of the biofeedback has a stronger impact on the minimum values of $T_{2}$ than on the maximum values, i.e. it has a stronger impact on La Niña (Fig. 4a). This is a consequence of the ecosystem response to ENSO: during La Niña, the mixed layer is shallow and phytoplankton growth is supported by strong upwelling and intense shortwave radiation. Whereas during El Niño, phytoplankton concentrations are low, which means that biomass-specific absorption has less influence on the heat fluxes. 

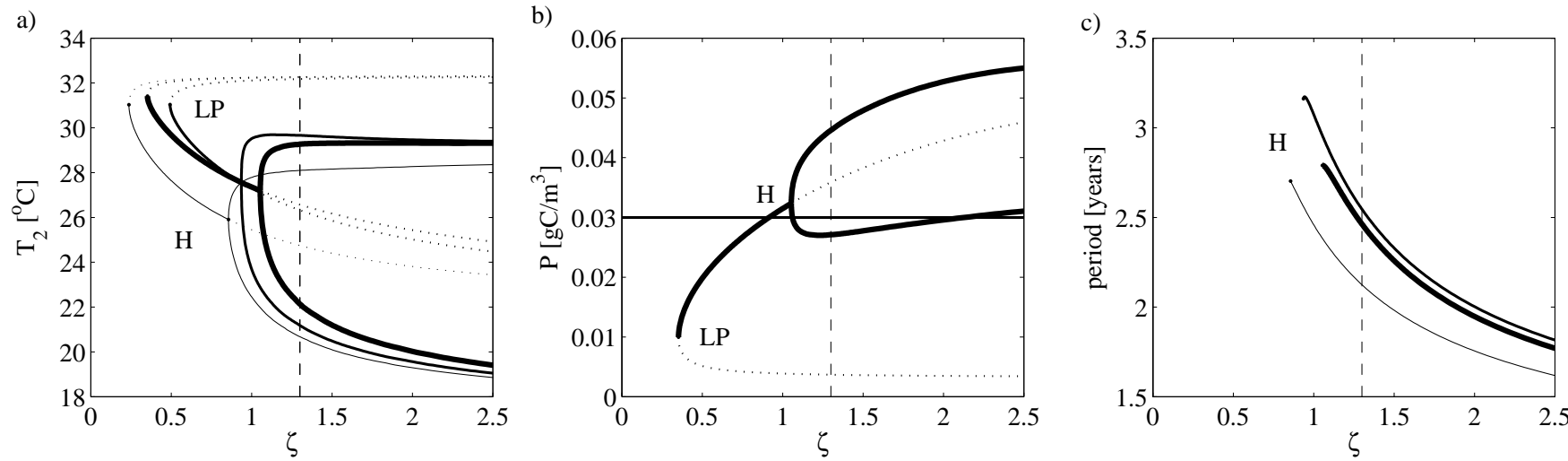

Fig. 5. (a) Eastern SST $T_{2}$, (b) phytoplankton P, and (c) ENSO period as a function of the upwelling efficiency $\zeta$ in the fully coupled model (bold curves, $k_{\mathrm{c}}=0.74 \mathrm{~m}^{2}(\mathrm{gC})^{-1}$ ) compared to a run without biology (thin curves, $k_{\mathrm{c}}=0$ ), and a run of the physical model with constant background phytoplankton concentration $\mathrm{P}=0.03 \mathrm{gC} \mathrm{m}^{-3}$ and $k_{\mathrm{c}}=0.74 \mathrm{~m}^{2}(\mathrm{gC})^{-1}$ (medium width); H: supercritical Hopf bifurcation; LP: limit point; solid lines: minimum and maximum of stable oscillation or stable steady state respectively; dotted lines: unstable steady state.

From the stand-alone ecosystem model perspective, $k_{\mathrm{c}}$ represents phytoplankton self-shading. Increasing the selfshading coefficient $k_{\mathrm{c}}$ in the stand-alone ecosystem model yields only slightly reduced phytoplankton concentrations (not shown). This supports the assumption of Gildor et al. (2003) that the direct effect of self-shading on the net phytoplankton concentration is negligible in tropical oceans, because phytoplankton concentrations are relatively low. However, we can not test the effect of $k_{\mathrm{c}}$ on the vertical chlorophyll profile using a simple box model that assumes a perfect vertical mixing of phytoplankton within the mixed layer. In fact, Marzeion et al. (2005) find that large changes in the simulated depth of the chlorophyll maximum in the eastern equatorial Pacific can be attributed to bio-optical coupling, with some evidence for the selfshading effect.

Using the simple chlorophyll-temperature relation $\operatorname{chl}\left[\mathrm{mg} \mathrm{m}^{-3}\right]=-\alpha\left(T_{2}-30^{\circ} \mathrm{C}\right)+0.05$, Timmermann and Jin (2002) found that marine biology mostly weakens La Niña, but hardly influences El Niño. However, we find a considerable influence also on El Niño, though its impact is weaker than on La Niña.The reason for this difference is that our NPZ-model yields higher phytoplankton concentrations also during El Niño compared to the chlorophyll-temperature relation used by Timmermann and Jin (2002) (Fig. 3c). If we tuned the parameters in our simple marine ecosystem model to reduce the offset between the empirical relationship and our model results, the magnitude of the phytoplankton warming effect during El Niño and during La Niña would be reduced. The qualitative results such as the prolongation of the ENSO period and reduction of the ENSO amplitude due to the marine biota are not affected. Comparability between the empirical relationship as used by Timmermann and Jin (2002) depends on the chlorophyll to carbon ratio, which, as mentioned above, is uncertain and may vary due to adaptation of the marine biota to their environment. Note that the empirical relationship by Timmermann and Jin (2002) is only a rough, not well defined estimate of the average chlorophyll concentration in a very large, ultimately hypothetical mixed layer box. It is derived from satellite data, which can only represent the surface chlorophyll concentration. Deep chlorophyll maxima, for example, are not captured. The empirical relationship should not be regarded as ground truth.

\subsection{Sensitivity to the upwelling efficiency}

The upwelling efficiency $\zeta$ has a direct effect on the longterm behaviour of the ecosystem model via the upwelling of nutrients and dilution of phytoplankton, and on the physical model via the upwelling of cold water. Figure 5 illustrates the qualitative behaviour of the coupled model (bold curves) with respect to changes of the upwelling efficiency $\zeta$ compared to the physical model without biology (thin curves). For the default value of $\zeta=1.3$, the heating of the surface water due to marine biology is stronger during $\mathrm{La}$ Niña than during El Niño. However, when $\zeta$ is increased, the heating during El Niño stays approximately the same, whereas the additional heating during La Niña decreases for more efficient upwelling. The curves of medium width illustrate the behaviour of the physical model assuming a constant background phytoplankton concentration of $\mathrm{P}=$ $0.03 \mathrm{gC} \mathrm{m}^{-3}$ in the eastern mixed layer. Again, we identify the overall heating due to marine biology (cf. Sect. 3.2). For weak upwelling efficiencies, ENSO turns into a stable steady state via a Hopf bifurcation. The highest temperatures during El Niño correspond to the run with constant P. This is because the ecosystem model responds to El Niño with lower phytoplankton concentrations compared to the constant $\mathrm{P}$ used. By contrast, the highest temperatures 
during La Niña are obtained for the fully coupled model: the ecosystem reacts to La Niña with much higher phytoplankton concentrations, which in turn causes additional heating and a weakening of La Niña.

\section{Conclusions}

To study the interaction between marine biology and the El Niño-Southern Oscillation, we derive a conceptual coupled ocean-atmosphere-ecosystem model. To this end, we extend Jin's nonlinear recharge model for the equatorial Pacific (Jin, 1998) by including a dynamical computation of the mixed layer depths and explicit expressions for short-wave, long-wave, latent and sensible heat fluxes. Marine biology influences ENSO, since the surface mixed layer heat budget depends on the absorption of short-wave radiation due to phytoplankton. Phytoplankton concentrations are calculated using a three-component (NPZ) ecosystem model (Edwards and Brindley, 1996; Edwards, 1997), which is why this study extends that of Timmermann and Jin (2002), who used an empirically derived phytoplankton-temperature relation. The coupling between the biological and the physical model emphasises two fundamental feedbacks. The physical system influences the ecological system via the shortwave radiation and the strength of the upwelling of nutrient rich water in the eastern Pacific. The feedback of the biology on the physical system is given by the change in the light attenuation due to the phytoplankton concentration.

In our simple coupled atmosphere-ocean-ecosystem model, ENSO forces an oscillation of the ecosystem. Sensitivity studies with respect to the parameters that describe the physical environment revealed that higher phytoplankton concentrations during La Niña are mostly due to stronger entrainment of nutrients by upwelling which is consistent with observational data (Strutton and Chavez, 2004). The increased short-wave radiation due to reduced cloud cover above the cold tongue during La Niña only has a small effect on the phytoplankton concentration. In turn, an increased phytoplankton concentration causes a stronger absorption of light. Consequently, including marine biology leads to a warming of the eastern SST during La Niña by about $1.5^{\circ} \mathrm{C}$ compared to the stand-alone physical model with clear water. The warming during El Niño amounts to about $1.1^{\circ} \mathrm{C}$. Hence the biological feedback causes a stronger impact on La Niña than on El Niño. By contrast, neglecting the ecosystem dynamics but assuming a constant background phytoplankton concentration in the Pacific cold tongue causes a stronger warming during El Niño than during La Niña. Using a simple chlorophyll-temperature relation, Timmermann and Jin (2002) found that marine biology mostly weakens La Niña and hardly influences El Niño. However, we find a reasonable (for certain parameter sets even higher) impact on El Niño as well. The reason is that our NPZ-model yields a relatively high phytoplankton concentration during El Niño compared to the chlorophylltemperature relation used by Timmermann and Jin (2002) (Fig. 3c).

The simple model employed has the advantage that its dynamical structure can be analysed systematically. However, it does not capture processes that have been shown to play a role in the bio-physical coupling effects on tropical climate variability, such as the vertical, zonal and meridional extents of phytoplankton anomalies that can drive changes in ocean currents (Marzeion et al., 2005; Sweeney et al., 2005; Lengaigne et al., 2007; Anderson et al., 2009; Löptien et al., 2009) and eventually changes in heat flux convergence and climate. Moreover, our simplified model does not resolve the dynamics of the annual cycle and consequently all annual cycle - ENSO interactions are neglected. Marzeion et al. (2005) finds that changes in the annual cycle induced by bio-physical coupling could in turn influence ENSO variability. The direct comparison of previous studies aimed at quantifying the bio-optical effects on tropical climate are hampered by the fact that different reference levels for the light attenuation in "clear" waters are used. Furthermore, different CGCMs have a different representation of the mean state, the eastern equatorial annual cycle and ENSO. It is hence not too surprising that the detailed response mechanisms to the biooptical parametrisations are quite different amongst models. Moreover, it was documented in an eddy-permitting ocean general circulation model experiment (Löptien et al., 2009) that bio-physical coupling may even enhance the level of near-surface eddy kinetic energy associated with Tropical Instability Waves (TIW). This may feed back onto ENSO, in particular during La Niña phases which are characterised by strong TIW activity and an associated equatorward transport of heat.

While at this stage the detailed effects of ocean colour on tropical climate appear to be highly model dependent, recent model simulations conducted with a hierarchy of models have clearly documented that the optical properties of phytoplankton have a discernible impact on tropical Pacific climate and its variability.

Acknowledgements. A. Timmermann is supported by the Japan Agency for Marine-Earth Science and Technology (JAMSTEC) through its sponsorship of the International Pacific Research Center and by the Office of Science (BER), US Department of Energy, Grant No. DE-FG02-07ER64469. The model analysis has been carried out using the numerical continuation software CONTENT. This is IPRC Publication \#747.

The service charges for this open access publication have been covered by the Max Planck Society.

Edited by: V. Lucarini

Reviewed by: two anonymous referees 


\section{References}

Anderson, W., Gnanadesikan, A., Hallberg, R., Dunne, J., and Samuels, B. L.: Impact of ocean color on the maintenance of the Pacific Cold Tongue, Geophys. Res. Lett., 34, L11609, doi:10.1029/2007GL030100, 2007.

Anderson, W., Gnanadesikan, A., and Wittenberg, A.: Regional impacts of ocean color on tropical Pacific variability, Ocean Sci., 5, 313-327, doi:10.5194/os-5-313-2009, 2009.

Ballabrera-Poy, J., Murtugudde, R. G., Zhang, R.-H., and Busalacchi, A. J.: Coupled ocean-atmosphere response to seasonal modulation of ocean color: Impact on interannual climate simulations in the tropical Pacific, J. Climate, 20, 353374, doi:10.1175/JCLI3958.1, 2007.

Barber, R. T. and Chavez, F. P.: Biological Consequences of El Niño, Science, 222, 1203-1210, doi:10.1126/science.222.4629.1203, 1983.

Bjerknes, J.: Atmospheric teleconnections from the equatorial Pacific, Mon. Weather Rev., 97, 163-172, 1969.

Bromwich, D., Monaghan, A., and Guo, Z.: Modeling the ENSO modulation of Antarctic climate in the late 1990s with Polar MM5, J. Climate, 17, 109-132, 2004.

Chavez, F. P., Strutton, P. G., Friederich, G. E., Feely, R. A., Feldman, G. C., Foley, D. G., and McPhaden, M. J.: Biological and Chemical Response of the Equatorial Pacific Ocean to the 1997-98 El Niño, Science, 286, 2126-2131, doi:10.1126/science.286.5447.2126, 1999.

Cloern, J. E., Grenz, C., and Vidergar-Lucas, L.: An empirical model of the phytoplankton chlorophyll : carbon ratio - the conversion factor between productivity and growth rate, Limnol. Oceanogr., 40, 1313-1321, doi:10.2307/2838689, 1995.

Collins, M., An, S.-I., Cai, W., Ganachaud, A., Guilyardi, E., Jin, F.-F., Jochum, M., Lengaigne, M., Power, S., Timmermann, A., Vecchi, G., and Wittenberg, A.: The Impact of Global Warming on the Tropical Pacific and El Niño, Nat. Geosci., 3, 391-397, doi:10.1038/ngeo868, 2010.

Edwards, A. M.: A Rational Dynamical-Systems Approach to Plankton Population Modelling, Ph.D. thesis, University of Leeds, 1997.

Edwards, A. M. and Brindley, J.: Oscillatory behaviour in a threecomponent plankton population model, Dynam. Stabil. Syst., 11, 347-370, doi:10.1080/02681119608806231, 1996.

Edwards, A. M., Wright, D. G., and Platt, T.: Biological heating effect of a band of phytoplankton, J. Marine Syst., 49, 89-103, doi:10.1016/j.jmarsys.2003.05.011, 2003.

Gildor, H., Sobel, A. H., Cane, M. A., and Sambrutto, R. N.: A role of ocean biota in tropical intraseasonal atmospheric variability, Geophys. Res. Lett., 30(9), 1460, doi:10.1029/2002GL016759, 2003.

Gill, A. E.: Atmosphere-Ocean Dynamics, Academic Press Inc., London, UK, 1982.

Gnanadesikan, A. and Anderson, W.: Ocean water clarity and the ocean general circulation in a coupled climate model, J. Phys. Oceanogr., 39, 314-332, doi:10.1175/2008JPO3935.1, 2009.

Guilyardi, E., Wittenberg, A., Fedorov, A., Collins, M., Wang, C., Capotondi, A., van Oldenborgh, G., and Stockdale, T.: Understanding El Niño in Ocean-Atmosphere General Circulation Models : progress and challenges, B. Am. Meteorol. Soc., 90, 325-340, doi:10.1175/2008BAMS2387.1, 2009.
Jin, F. F.: Tropical ocean-atmosphere interaction, the Pacific cold tongue and the El Niño-Southern Oscillation, Science, 274, 7678, doi:10.1126/science.274.5284.76, 1996.

Jin, F. F.: A Simple Model for the Pacific Cold Tongue and ENSO, J. Atmos. Sci., 2458-2469, 1998.

Jin, F. F. and Neelin, J. D.: Modes of interannual tropical oceanatmosphere interaction - A unified view. Part I: Numerical results, J. Atmos. Sci., 50, 3477-3502, 1993.

Kraus, E. B. and Turner, J. S.: A one-dimensional model of the seasonal thermocline. II: The general theory and its consequences, Tellus, 19, 98-109, doi:10.1111/j.21533490.1967.tb01462.x, 1967.

Kuznetsov, Y. A. and Levitin, V. V.: CONTENT: A multiplatform environment for continuation and bifurcation analysis of dynamical systems, Tech. rep., Centrum voor Wiskunde en Informatica, Amsterdam (Netherlands), 1997.

Latif, M., Anderson, D., Barnett, T., Cane, M., Kleeman, R., Leetmaa, A., O'Brien, J., Rosati, A., and Schneider, E.: A review of predictability and prediction of ENSO, J. Geophys. Res., 103, 14375-14393, 1998.

Lengaigne, M., Menkes, C., Aumont, O., Gorgues, T., Bopp, L., André, J.-M., and Madec, G.: Influence of the oceanic biology on the tropical Pacific climate in a Coupled General Circulation Model, Clim. Dynam., 28, 503-516, doi:10.1007/s00382-0060200-2, 2007.

Löptien, U., Eden, C., Timmermann, A., and Dietze, H.: Effects of biologically induced differential heating in an eddy-permitting coupled ocean-ecosystem model, J. Geophys. Res., 114, C06011, doi:10.1029/2008JC004936, 2009.

Manizza, M., Quéré, C. L., Watson, A., and Buitenhuis, E.: Biooptical feedbacks among phytoplankton upper ocean physics and sea-ice in a global model, Geophys. Res. Lett., 32, L05603, doi:10.1029/2004GL020778, 2005.

Marzeion, B., Timmermann, A., Murtugudde, R., and Jin, F.-F.: Biophysical Feedbacks in the Tropical Pacific, J. Climate, 18, 58-70, 2005.

Murtugudde, R., Beauchamp, J., and Busalacchi, A.: Effects of Penetrative Radiation on the Upper Tropical Ocean Circulation, J. Climate, 15, 470-486, 2002.

Nakamoto, S., Kumar, S., Oberhuber, J., Ishizaka, J., Muneyama, K., and Frouin, R.: Response of the equatorial Pacific to chlorophyll pigment in a mixed layer isopycnal ocean general circulation model, Geophys. Res. Lett., 28(10), 2021-2024, doi:10.1029/2000GL012494, 2001.

Neelin, J. D.: The slow sea surface temperature mode and the fastwave limit: Analytic theory for tropical interannual oscillations and experiments in a hybrid coupled model, J. Atmos. Sci., 48, 584-606, 1991.

Philip, S. and van Oldenborgh, G.: Shifts in ENSO coupling processes under global warming, Geophys. Res. Lett., 33, L11704, doi:10.1029/2006GL026196, 2006.

Platt, T., Sathyendranath, S., Edwards, A. M., Broomhead, D. S., and Ulloa, O.: Nitrate supply and demand in the mixed layer of the ocean, Mar. Ecol.-Prog. Ser., 254, 3-9, 2003.

Schopf, P. S. and Cane, M. A.: On equatorial dynamics, mixed layer physics and sea surface temperature, J. Phys. Oceanogr., 13, 917-935, 1983.

Seager, R., Zebiak, S. E., and Cane, M. A.: A Model for the Tropical Pacific Sea Surface Temperature Climatology, J. 
Geophys. Res., 93, 1265-1280, 1988.

Seo, H., Jochum, M., Murtugudde, R., and Miller, A.: Effect of ocean mesoscale variability on the mean state of tropical Atlantic climate, Geophys. Res. Lett., 33, L09606, doi:10.1029/2005GL025651, 2006.

Steele, J. H. and Henderson, E. W.: A simple plankton model, Am. Nat., 117, 676-691, 1981.

Strutton, P. and Chavez, F.: Biological heating in the equatorial Pacific: Observed variability and potential for real-time calculation, J. Climate, 17, 1097-1109, 2004.

Sweeney, C., Gnanadesikan, A., Griffies, S., Harrison, M., Rosati, A., and Samuel, B.: Impacts of shortwave penetration depth on the large-scale circulation and heat transport, J. Phys. Oceanogr., 35, 1103-1119, 2005.

Taylor, A. H., Geider, R. J., and Gilbert, F. J. H.: Seasonal and latitudinal dependencies of phytoplankton carbon-to-chlorophyll a ratios: results of a modelling study, Mar. Ecol.-Prog. Ser., 152, 51-66, doi:10.3354/meps152051, 1997.

Timmermann, A. and Jin, F.-F.: Phytoplankton influences on tropical climate, Geophys. Res. Lett., 29(23), 2104, doi:10.1029/2002GL015434, 2002.

Timmermann, A., Latif, M., Bacher, A., Oberhuber, J., and Roeckner, E.: Increased El Niño frequency in a climate model forced by future greenhouse warming, Nature, 398, 694-696, doi:10.1038/19505, 1999.

van Oldenborgh, G., Burgers, G., and Tank, A. K.: On the El Niño Teleconnection to spring precipitation in Europe, Int. J. Climatol., 20, 565-574, doi:10.1002/(SICI)1097-0088(200004), 2000.
Wang, Y., Xie, S.-P., Xu, H., and Wang, B.: Regional model simulations of marine boundary layer clouds over the Southeast Pacific off South America. Part I: Control experiment, Mon. Weather Rev., 132, 274-296, 2004.

Wang, J., Cota, G., and Comiso, J.: Phytoplankton in the Beaufort and Chukchi Seas: Distribution, dynamics, and environmental forcing, Deep-Sea Research Pt. II, 52, 33553368, doi: 10.1016/j.dsr2.2005.10.014, 2005.

Wetzel, P., Maier-Reimer, E., Botzet, M., Jungclaus, J., Keenlyside, N., and Latif, M.: Effects of ocean biology on the penetrative radiation in a coupled climate model, J. Climate, 19, 3973-3987, 2006.

Xie, S.-P.: Effects of Seasonal Forcing on Latitudinal Asymmetry of the ITCZ, J. Climate, 9, 2945-2950, 1996.

Yu, J.-Y. and Mechoso, C.: Links between annual variations of Peruvian stratocumulus clouds and of SST in the eastern equatorial Pacific, J. Climate, 12, 3305-3318, 1999.

Zhang, R.-H., Busalacchi, A. J., Wang, X., Ballabrera-Poy, J., Murtugudde, R. G., Hackert, E. C., and Chen, D.: Role of ocean biology-induced climate feedback in the modulation of El Niño-Southern Oscillation, Geophys. Res. Lett., 36, 1-6, doi:10.1029/2008GL036568, 2009. 